Article

\title{
HPLC-DAD Determination of Iodide in Mineral Waters on Phosphatidylcholine Column
}

\author{
Małgorzata Tatarczak-Michalewska, Jolanta Flieger* ${ }^{\mathbb{D}}$, Justyna Kawka, Wojciech Flieger \\ and Eliza Blicharska \\ Department of Analytical Chemistry, Medical University of Lublin, Chodźki 4A, 20-093 Lublin, Poland; \\ malgorzatatatarczakmichalewska@umlub.pl (M.T.-M.); justyna.kawka@umlub.pl (J.K.); wwoj24@wp.pl (W.F.); \\ bayrena@tlen.pl (E.B.) \\ * Correspondence: j.flieger@umlub.pl; Tel./Fax:+48-81448-7180
}

Received: 24 February 2019; Accepted: 26 March 2019; Published: 29 March 2019

check for updates

\begin{abstract}
Iodine is an essential nutrient necessary for the production of thyroid hormones. A valuable source of iodide, which is the bio-available iodine form could be mineral waters offered by different spas. In this work, the method capable of direct determination of iodide in mineral water samples based on IAM liquid chromatography on the phosphatidylcholine column (IAM.PC.DD2 Regis HPLC) with DAD detection without sample pretreatment or any pre-concentration steps is presented. The calibration graph for iodide was linear in the range of $0.5-10.0 \mathrm{mg} \mathrm{L}^{-1}$ with a correlation coefficient of 0.9996 . The limit of detection was $22.84 \mathrm{ng} \mathrm{mL}^{-1}$. The relative recoveries were in the interval of $98.5-100.2 \%$ and the repeatability, expressed as a relative standard deviation (RSD) was less than 5\%. The RSA (Response Surface Analysis) investigated the effect of the sample concentration and the injection volume. The iodide concentrations in the mineral water samples ranged from 0.58 to $2.88 \mathrm{mg} \mathrm{L}^{-1}$. The accuracy of the method was assessed through independent analysis by ICP-MS. Iodide levels measured by these two procedures did not significantly differ. The effects of interfering ions like $\mathrm{HCO}_{3}{ }^{-}, \mathrm{Cl}^{-}, \mathrm{SO}_{4}{ }^{2-}, \mathrm{F}^{-}$, and $\mathrm{Br}^{-}$were also tested. The analysis has shown insignificant differences in the values of the iodide peak area and its height measured in multicomponent mixtures with an error smaller than $5 \%$.
\end{abstract}

Keywords: phosphatidylcholine; iodide anions; mineral waters; sustainable chemistry

\section{Introduction}

Iodine belongs to an essential micronutrient. For the human body, it is an exogenous element that can only be taken through drinking water or various foods. Iodine is absorbed by the gastrointestinal tract in the form of iodide becoming the key component of the thyroid hormones including thyroxin (T4) and triiodothyronine (T3) [1]. Currently, it is estimated that about 2 billion people in the world are affected by iodine deficiencies, including $30 \%$ of which are children [2,3].

Iodine Deficiency Disorders (IDD) cause an endemic goitre, cretinism, and are particularly dangerous for pregnant women since they can lead to fetal brain damage and miscarriage [4-6]. Iodine intake for an adult has been estimated to be $1 \mu \mathrm{g}$ per $\mathrm{kg}$ body weight daily [7]. The World Health Organization (WHO) iodine prophylaxis program has recommended obligatory salt iodization of $30 \pm 10 \mathrm{mg} \mathrm{KI} / \mathrm{kg}$, and additional supplementation for pregnant and lactating women by 150-200 $\mu \mathrm{g}$ iodine per day [2]. The U.S. Institute of Medicine (IOM) has recommended even higher daily allowance (RDA in $\mu \mathrm{g} \mathrm{d}^{-1}$ ) of iodine as follows for adults 150 (RDA), pregnant women: 220 (RDA), and lactating women: 290 (RDA) [8].

Iodine is found mainly as iodide, iodate, and iodine-organic compounds in the environment $[9,10]$. These forms are converted to one another rapidly. However, iodide is considered to be the most 
mobile and bioavailable iodine form [10]. Several methods have been described in order to determine the iodine. In most of them, the iodine species were derivatized to iodide, which, subsequently, was determined by a high performance liquid chromatography (HPLC) [11] or to organo-iodine forms further analyzed by a gas chromatography-mass spectrometry (GC-MS) [12]. However, the above methods possess very important limitations such as time-consuming derivatization steps and restricted requirements devoted to the iodine scavenger. The determination of inorganic iodine species is possible by an ion chromatography (IC) with conductivity detection characterizing with poor sensitivity for quantification in some applications. The limitation of IC usability is the presence of chlorides in the matrix, which requires sample pretreatment by the use of an on-guard silver cartridge [13,14].

Other methods recommended for iodine determination go as follows: spectrophotometry [15], titration [16], and the ion-selective electrode [17]. In the case of conventional iodometric titration, the main drawback is false estimation because of interfering oxidizing agents [14]. In turn of electrochemical determination, unsatisfactory precision has been emphasized [18]. Furthermore, the main disadvantages in using electrochemical detection are unvarying pre-treatment steps [19-21]. The spectrophotometric method, which is based on the Sandell and Kolthoff reaction [15], is one of the oldest methods utilizing the iodine-catalyzed redox reaction between cerium (IV) and arsenic (III). It has been applied mainly because it does not require expensive instrumentation. However, a catalytic effect of sodium and iron leading to false high values of iodine has been demonstrated [22].

More sophisticated methods such as ion-pair liquid chromatography [23] and Inductively Coupled Plasma Mass Spectrometry, ICP-MS [24], transient isotachophoresis-capillary zone electrophoresis [25], and electroanalysis [26], are recommended as methods for providing reliable and accurate results. However, they have been excluded from routine analysis in many countries due to the high costs. The Dionex application note (Application Note 236) described the use of a silica-based column that incorporates hydrophobic, weak anion-exchange, and ion-exclusion properties (the Acclaim Mixed-Mode WAX-1) to determine iodide in high ionic strength samples such as seawater [27]. In another application note (Application Note 239), an IC system was used with a column designed for the separation of polarizable anions (the Thermo Scientific ${ }^{\mathrm{TM}}$ Dionex $^{\mathrm{TM}}$ IonPac ${ }^{\mathrm{TM}}$ AS20 column) [28]. Conductivity and UV detection showed similar linearity and LOD on the level of $15 \mu \mathrm{g} / \mathrm{L}$. Linear response to iodide was confirmed between 50-250 $\mathrm{kg} / \mathrm{L}$. Determinations of iodide in saline matrixes was accurate with recoveries ranging from $93 \%$ to $113 \%$. To determine the concentration of iodide by an HPLC system, the fluorescence detector can also be applied [29,30]. Only one work has described handmade created phosphatidylcholine stationary phases for the chromatographic separation of a few inorganic anions [31]. Obtained stationary phases have been prepared by loading liposomes of dimyristolyphosphatidylcholine (DMPC) onto reversed-phase columns. Currently, Immobilized Artificial Membranes are being prepared commercially by phosphatidylcholine analogues chemically bonded to a propylamino-silica core [32]. As they can efficiently simulate bio-membrane permeation [33,34], these columns are useful in permeability studies or predicting the therapeutic effects of many substances such as (-)-epicatechin conjugates [35], various model drugs [36,37], flavonoids [38], statins [39], and NSAIDs [40].

Taking into account the importance of iodine consumption, it is clear that an analytical method for inorganic iodine determination in different food products that could be easily applied is needed. Therefore, the aim of this work is to develop an analytical method based on IAM-HPLC-DAD capable of quantifying iodide in mineral water samples as a source of iodine supplementation. The proposed methodology is focused on the application of commercially available phosphatidylcholine column (IAM.PC.DD2 Regis HPLC) for the first time, which is able to retain iodide even by the use of water containing $\mathrm{NaCl}$ as an eluent, obtain enough capacity necessary for iodide determination in a complex matrix, sufficient sensitivity necessary for trace analysis, selectivity against interfering ions, and using a small sample volume. Obtained results were compared with the reliable ICP-MS method as a reference. 


\section{Results and Discussion}

\subsection{Effect of Experimental Variables}

To establish the best conditions for the determination of iodide, the high-performance liquid chromatography method was optimized with respect to sodium chloride concentration in the mobile phase. The influence of $\mathrm{NaCl}$ on the retention factor $(k)$, symmetry $\left(A_{\mathrm{s}}\right)$, and efficiency of the peaks (N) may be analyzed on the basis of the data included in Table 1 and the examples of chromatograms obtained under studied conditions (Figure 1). The results show that the retention time increased up to 6 min and then gradually decreased with increasing concentration of $\mathrm{NaCl}$ in the mobile phase. A concentration of $30 \mathrm{mM}$ was chosen in subsequent experiments since it enabled the highest efficiency expressed as the theoretical plates number (above $3000 \mathrm{~N}$ ) and the most beneficial peak's symmetry ( $A_{\mathrm{s}}$ smaller then 2$)$. It has been previously established that anions are retained on a phospholipid monolayer on the basis of a solvation-dependent mechanism but considering presence of the quaternary ammonium groups $\left(\mathrm{N}^{+}\right)$on the surface, an anion-exchange process can also contribute to their retention [31]. It is clear that an eluent's ionic strength influences both retention mechanisms. Therefore, all peak's parameters undergo improvement with increasing $\mathrm{NaCl}$ concentration in the mobile phase.

Table 1. Effect of $\mathrm{NaCl}$ concentration in the mobile phase in the range of 1 to $30 \mathrm{mM}$ for the KI retention factor $(k)$, the peak symmetry factor $\left(A_{\mathrm{S}}\right)$, and the theoretical plates number $(\mathrm{N})$. The column was IAM.PC.DD2 Regis HPLC Agilent Technologies, flow rate of the mobile phase was $0.5 \mathrm{~mL} / \mathrm{min}$, injected volume $3 \mu \mathrm{L}$, and analytical wavelength of $226 \mathrm{~nm}$.

\begin{tabular}{cccc}
\hline $\begin{array}{c}\text { NaCl Concentration } \\
{[\mathbf{m M}]}\end{array}$ & Retention Factor $\boldsymbol{k}$ & Symmetry Factor As * & $\begin{array}{c}\text { Theoretical Plates } \\
\text { Number N (EUP) ** }\end{array}$ \\
\hline 1 & $2.83( \pm 0.08)$ & $2.73( \pm 0.05)$ & $295( \pm 97)$ \\
5 & $3.19( \pm 0.07)$ & $2.90( \pm 0.04)$ & $1191( \pm 147)$ \\
10 & $3.57( \pm 0.06)$ & $2.97( \pm 0.07)$ & $1973( \pm 198)$ \\
15 & $3.59( \pm 0.10)$ & $2.74( \pm 0.08)$ & $2352( \pm 116)$ \\
20 & $3.59( \pm 0.07)$ & $2.57( \pm 0.06)$ & $2794( \pm 174)$ \\
25 & $3.50( \pm 0.08)$ & $2.32( \pm 0.07)$ & $3082( \pm 196)$ \\
30 & $3.39( \pm 0.06)$ & $1.91( \pm 0.06)$ & $3136( \pm 177)$ \\
\hline
\end{tabular}

All calculations were performed using the HSM program. * The HSM program uses the following equation to calculate asymmetry: $A s=1 / 2(1+\mathrm{B} / \mathrm{A})$, where $\mathrm{A}$ and $\mathrm{B}$ are evaluated at a $5 \%$ peak height of an appropriate peak.

** The following equation is used to calculate the number of theoretical plates according to EUP standards: $\mathrm{N}=5.54$ $\left(\mathrm{RT} / \mathrm{W}_{1 / 2}\right)$, where $\mathrm{RT}$ is the actual retention time of the appropriate peak, W equals the peak width obtained by drawing tangents to each side of the peak and calculating the distance between the two points where the tangents meet a line that runs parallel to the baseline at half peak-height. 


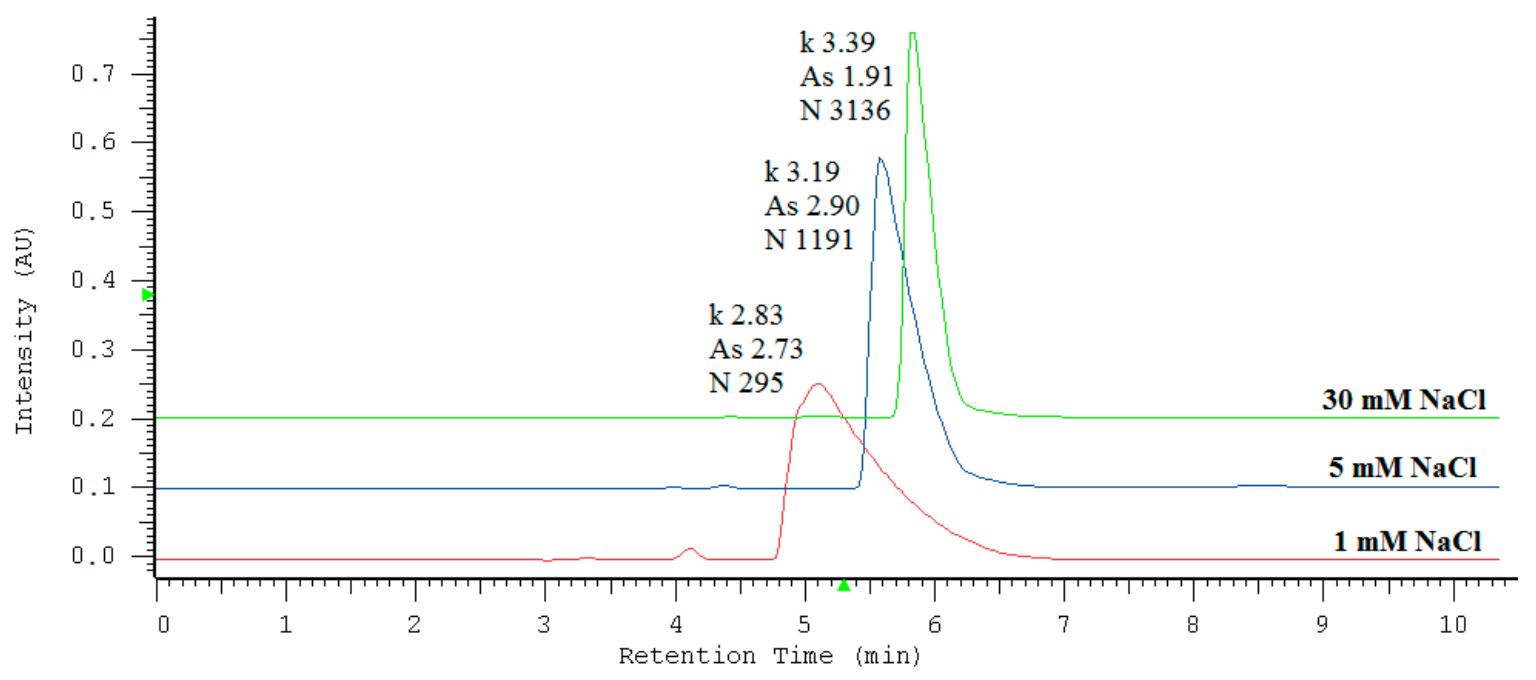

Figure 1. Effect of different concentrations of $\mathrm{NaCl}$ in the eluent system on iodide retention, peak symmetry, and efficiency.

Chromatographic method optimization was carried out by applying a Response Surface Methodology (RSM). This procedure was applied to obtain optimum chromatographic conditions to avoid volume or concentration overloading, which manifests itself in the form of distorted peak shapes. It allowed the evaluation of the relationship between a set of controlled experimental factors such as injection volume or sample concentration and obtained results expressed as the peak symmetry and the theoretical plate number. The obtained dependency model can be described by the following second-degree polynomial equation.

$$
Z=\beta_{0}+\beta_{1} C+\beta_{2} C^{2}+V
$$

where $\mathrm{Z}$ is a dependent variable, $\mathrm{C}$ is the concentration, and $\mathrm{V}$ is the injection volume.

In terms of matching variables to this model, the relationship between concentration versus the injection volume and the theoretical plate's number proved to be the best fit. The significance of $F$ statistics in both cases shows that, in each of them, at least one independent variable (concentration or volume) affects the dependent variable ( $\mathrm{N}$ or $A \mathrm{~s}$ ). The response surfaces are shown in Figure 2A,B and Table 2.

Table 2. Second-degree polynomial model parameters.

\begin{tabular}{ccc}
\hline Parameters & As & N \\
\hline C & $0.021(0.005)$ & $-49.876(11.734)$ \\
I(C2) & $-0.0001(0.00004)$ & $0.204(0.112)$ \\
V & $0.037(0.006)$ & $-113.931(14.506)$ \\
constant & $0.646(0.100)$ & $8360.409(257.425)$ \\
observations & 35 & 35 \\
$\mathrm{R}^{2}$ & 0.812 & 0.853 \\
Adjusted $\mathrm{R}^{2}$ & 0.794 & 0.839 \\
Residual Std Error & $0.209(\mathrm{df}=31)$ & $538.961(\mathrm{df}=31)$ \\
F statistic & $44.771(\mathrm{df}=3 ; 31)$ & $60.201(\mathrm{df}=3 ; 31)$ \\
\hline
\end{tabular}




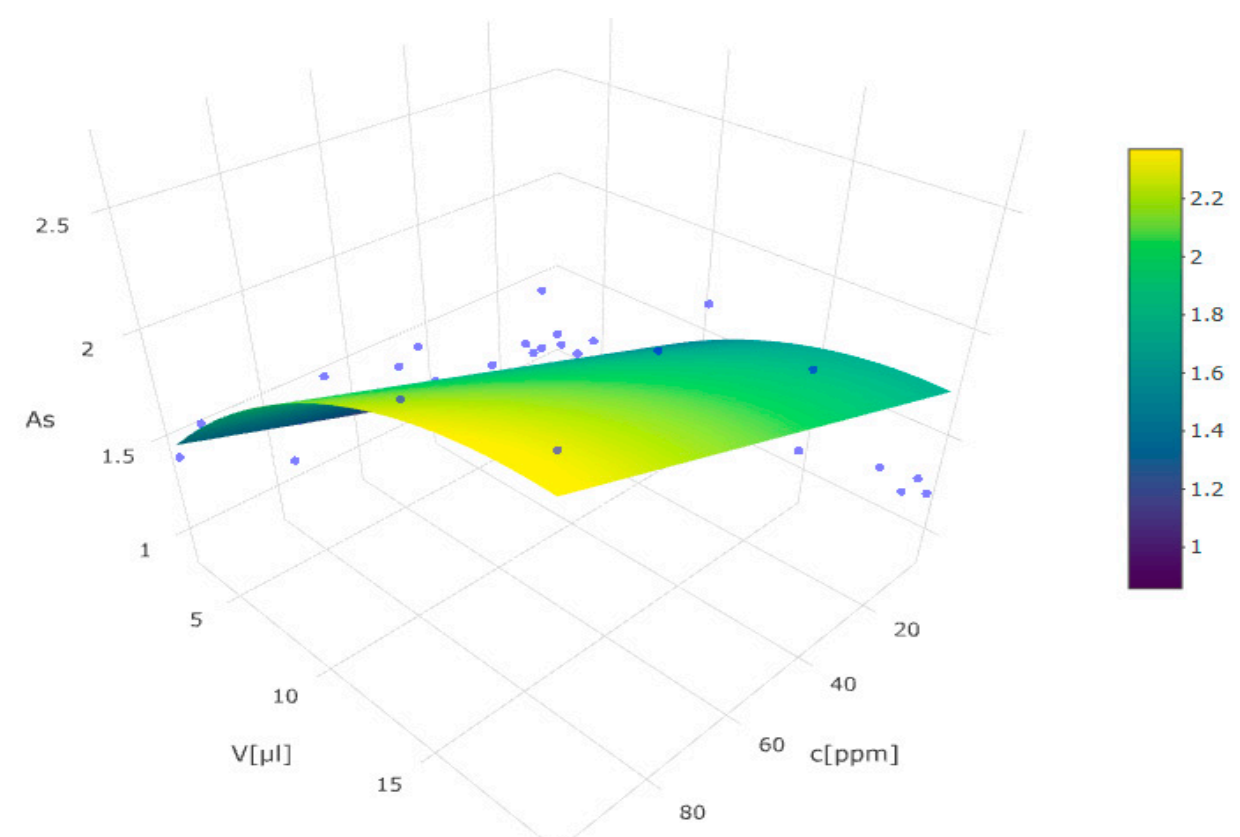

A

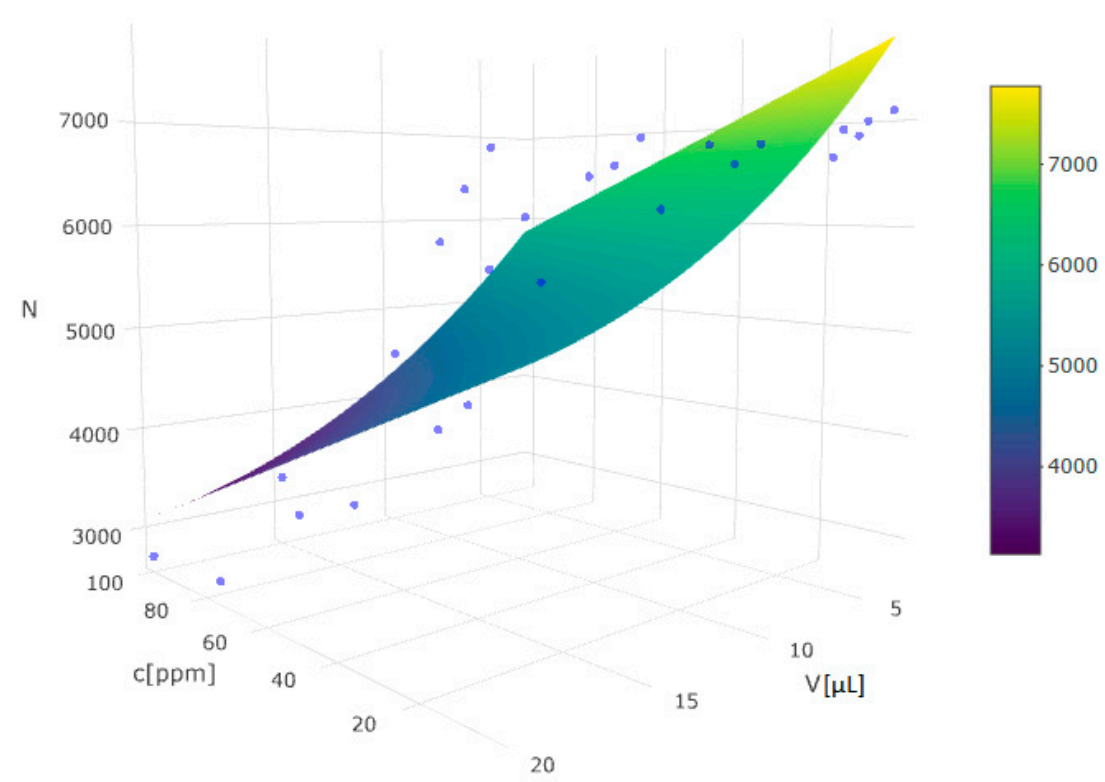

B

Figure 2. Effect of iodide concentration (C) and injection volume (V) on peak symmetry: As-(A), and system efficiency: N-(B) by the Response Surface Analysis (RSA).

In the light of a sequence of designed experiments analyzed by the RSA, the best symmetry of the peak and the system efficiency was obtained by decreasing the sample volume and its concentration. Due to the optimization of operational factors, subsequent quantifications were performed by applying $3 \mu \mathrm{L}$ of diluted samples. Furthermore, analyzed samples did not require any pre-concentration steps to obtain an optimal response. Such a low sample volume $(3 \mu \mathrm{L})$ is beneficial when taking into account the possibility of extending the chromatographic column lifetime and avoiding overloading. Other LC-UV applications utilizing the ion-exchange separation mechanism for iodide determination require much bigger sample injection volumes in the range of 25 to $500 \mu \mathrm{L}[11,41-43]$. 


\subsection{Analytical Quality Control}

The parameters such as linearity, the limit of detection, and quantification are presented in Table 3.

Table 3. The linear regression parameters obtained for the calibration curves of iodide ions.

\begin{tabular}{cccccccc}
\hline \multirow{2}{*}{$\begin{array}{c}\text { LOD }^{*} \\
{\left[\mathrm{mg} \mathrm{L}^{-1}\right]}\end{array}$} & \multirow{2}{*}{ LOQ $^{*}$} \\
{$\left[\mathrm{mg} \mathrm{L}^{-1}\right]$} & \multirow{2}{*}{$\begin{array}{c}\text { Linear Range } \\
{\left[\mathbf{m g ~ L}^{-1}\right]}\end{array}$} & \multicolumn{5}{c}{$\begin{array}{c}\text { Regression Equation } \\
(\mathbf{y}=\mathbf{a x}+\mathbf{b})\end{array}$} \\
\cline { 4 - 8 } & & & $\mathbf{a} \pm \mathbf{S}_{\mathbf{a}}$ & $\mathbf{b} \pm \mathbf{S}_{\mathbf{b}}$ & $\mathbf{r}$ & $\mathbf{S}_{\mathbf{e}}$ & $\mathbf{F}$ \\
\hline 0.02284 & 0.06852 & $0.5-10.0$ & $16156.1( \pm 175.33)$ & $-2264.6( \pm 902.5)$ & 0.9996 & 1361.5 & 8491.4 \\
\hline
\end{tabular}

${ }^{*}$ Number of calibration points: 8 . ${ }^{* *} \mathrm{~S}_{\mathrm{a}}$ : the standard deviation of the slope, $\mathrm{S}_{\mathrm{b}}$ : the standard deviation of the intercept, $\mathrm{S}_{\mathrm{e}}$ : the standard error of estimate, $\mathrm{F}$-Fisher F Statistic.

The applicability of the proposed method was evaluated by analyzing real canal water samples. Since no positive samples were found regarding the content of iodides, the samples were spiked with the analyte at three concentration levels $\left(2,5\right.$, and $\left.10 \mathrm{mg} \mathrm{L}^{-1}\right)$. The results are presented in Table 4 . Relative recovery values were in the range $98.5-100.2 \%$, which indicates the absence of the matrix effect on the proposed method.

Table 4. The percentage of recoveries $(R)$ of real canal water samples spiked with the analyte.

\begin{tabular}{ccccc}
\hline Sample & Added [mg L $\left.{ }^{-\mathbf{1}}\right]$ & $\begin{array}{c}\text { Measured Mean } \pm \text { SD } \\
(\mathbf{n}=\mathbf{3})\left[\mathbf{m g ~ L}^{-\mathbf{1}}\right]\end{array}$ & $\begin{array}{c}\text { Percentage of } \\
\text { Recovery }\end{array}$ & RSD \% \\
\hline \multirow{3}{*}{ Canal water } & 0 & 0 & - & - \\
& 2 & $1.97( \pm 0.07)$ & 98.5 & 3.55 \\
& 5 & $4.96( \pm 0.22)$ & 99.2 & 4.43 \\
& 10 & $10.02( \pm 0.46)$ & 100.2 & 4.59 \\
\hline
\end{tabular}

\subsection{The Mineral Water Sample Analysis}

The optimized procedure (IAM-HPLC-DAD) was applied to determine iodide in mineral water samples. Exemplary chromatogram of the investigated water sample with DAD iodide peak identification is presented in Figure 3. Table 5 shows iodide content in six selected natural, mineral waters from Polish resorts with a long tradition in the field of spa medicine. In samples investigated, a single peak occurred at the same retention time, which was measured for a standard iodide. Furthermore, the absorption spectrum measured throughout the chromatographic peak exhibited a maximum at $226 \mathrm{~nm}$, which is characteristic for the iodide. The identity of the iodide was confirmed by retention time and absorption spectrum for the up-and downslope. The coefficient of agreement between the standard spectrum recorded under defined chromatographic conditions and the examined sample was 0.9984 . 


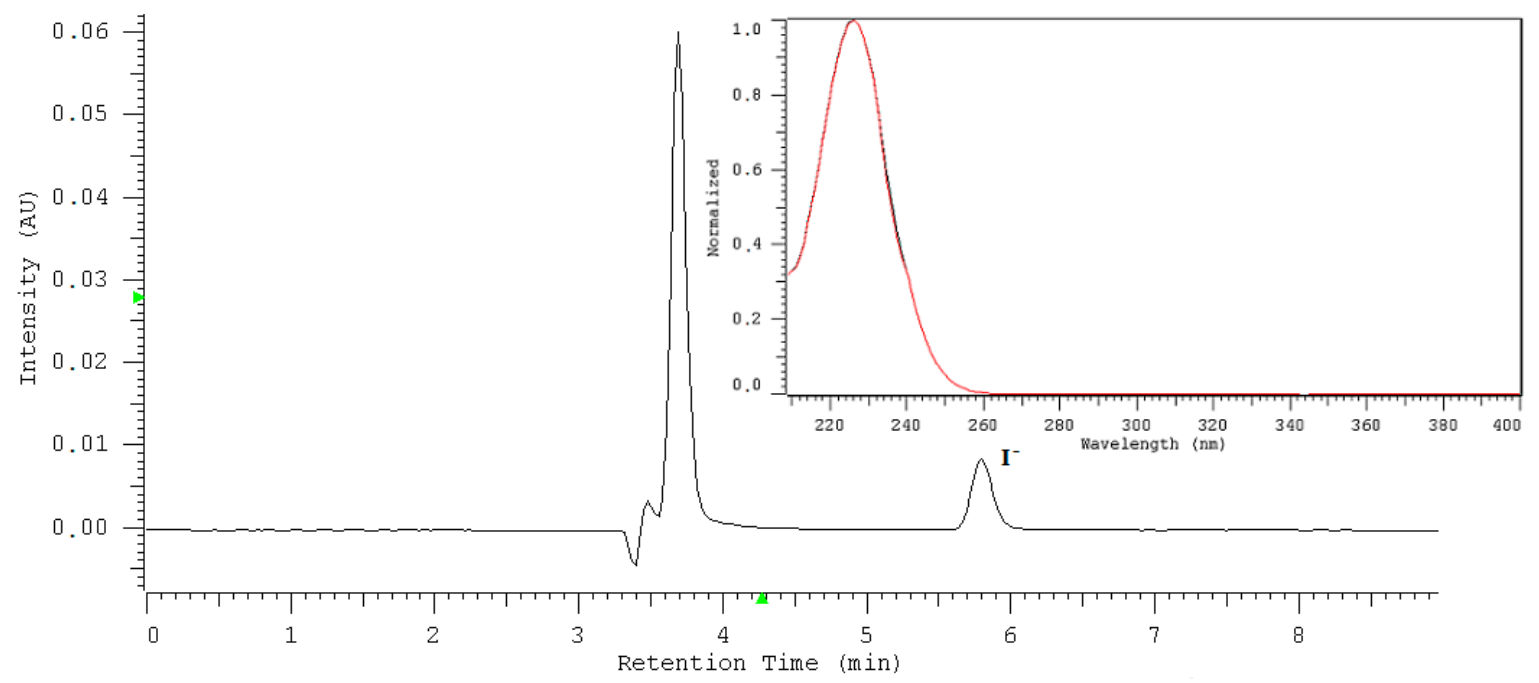

Figure 3. Chromatogram of sample W3. Insert: UV-absorption spectra of iodide in sample W3 recorded in the range of 190 to $400 \mathrm{~nm}$. Conditions: stationary phase: IAM.PC.DD2 Regis HPLC $\left(4.6 \times 150 \mathrm{~mm}, 10 \mu \mathrm{m}\right.$, pore size: $300 \AA$ ) , mobile phase $30 \mathrm{mM} \mathrm{NaCl} /$ water, the flow rate $0.5 \mathrm{~mL} \mathrm{~min}^{-1}$, detection $226 \mathrm{~nm}$.

Iodide was analyzed quantitatively with an external standard curve. The ICP-MS, which is considered to be fast, accurate, robust, and specific, was used as the reference method.

The content of iodides declared by producers differs significantly from the value measured both by HPLC and ICP-MS. In some cases, quantities declared by producers may require re-evaluation to reach true levels. However, the experimental values quantified on the phosphatidylcholine column do not differ from the values measured by the reference ICP-MS method. To investigate the agreement between measurements made by two methods, the relationship between measurements from the IAM-HPLC against those from the reference method was prepared. The linear regression analysis for this dataset possesses the slope close to one and the low value of the intercept, which only differs a little from zero. This indicates excellent statistical compatibility of results obtained by both compared methods.

$$
\begin{gathered}
\mathrm{y}(\mathrm{IAM}-\mathrm{HPLC})=0.9607( \pm 0.02899) \times(\mathrm{ICP}-\mathrm{MS})+0.1379( \pm 0.04619) \\
\mathrm{R}^{2}=0.9856, \mathrm{~S}_{\mathrm{e}}=0.1056, \mathrm{~F}=1098.01
\end{gathered}
$$

Table 5. Iodide content in selected mineral waters $(\mathrm{n}=3$ each) analyzed by HPLC-DAD on IAM.PC.DD2

\begin{tabular}{|c|c|c|c|c|c|}
\hline Sample & $\begin{array}{c}\text { Contents Declared } \\
{\left[\mathrm{mg} \mathrm{L}^{-1}\right]}\end{array}$ & $\begin{array}{c}\text { IAM.PC.DD2 Regis HPLC } \\
\text { Agilent Technologies }\left[\mathrm{mg} \mathrm{L}^{-1}\right] \\
\text { Mean } \pm \text { SD }\end{array}$ & Relative Bias * (\%) & $\begin{array}{l}\text { ICP-MS }\left[\mathrm{mg} \mathrm{L}^{-1}\right] \\
\quad \text { Mean } \pm \text { SD }\end{array}$ & Relative Bias ** $(\%)$ \\
\hline 2 & 2.49 & $0.84( \pm 0.07)$ & -66.2 & $0.69( \pm 0.03)$ & -72.2 \\
\hline 3 & 2.50 & $2.88( \pm 0.03)$ & 15.2 & $2.72( \pm 0.02)$ & 8.8 \\
\hline 6 & 4.43 & $1.60( \pm 0.06)$ & -63.8 & $1.56( \pm 0.02)$ & -64.8 \\
\hline
\end{tabular}
Regis HPLC Agilent Technologies and ICP-MS.

${ }^{*}$ Relative bias $(\%)=($ value from HPLC - Contents declared $) \times 100 /$ Contents declared. ${ }^{* *}$ Relative bias

$(\%)=($ value from ICP-MS - Contents declared $) \times 100 /$ Contents declared.

The linear regression might explain the bivariate relationship, which exists between two sets of measurements. Thus, the strength, form, and direction of a relationship can be identified but sometimes this approach is not recommended for comparative analyses [44]. A very useful data visualization 
tool is the Bland-Altman plot (B \& A is known as Tukey Mean-Difference plot). When comparing two sets of measurements for the same variable made by different instruments, it is often required to determine whether the instruments are in agreement or not. The B\&A plot is a simple way to evaluate the bias between the mean differences of measurements done by two methods. It is a kind of scatterplot of differences of two paired measurements against the average of these measurements. The average of two measurements is the best way to estimate the true mean. Bland and Altman say that, if the points are between the limits of agreement constructed as a $95 \%$ confidence interval for the difference, then these two instruments agree [45-47].

The gap between the $X$-axis and the blue line (Figure 4) represents the difference between readings from two measurement instruments. The mean value (0.086) is significantly different from zero $(p=0.004)$. This indicates that, on average, HPLC measurements are higher by about 0.086 units than ICP.MS. Except for one point belonging to sample W4, all observations are between the lower and upper bounds of the $95 \%$ confidence interval, which means that these two methods of measuring agree. Furthermore, Bland and Altman suggest checking the assumption of the normal distribution of differences. Figure 5 shows that there is no significant deviation of differences from the normal distribution. This hypothesis was also checked by the Shapiro-Wilk test $(p=0.52)$.

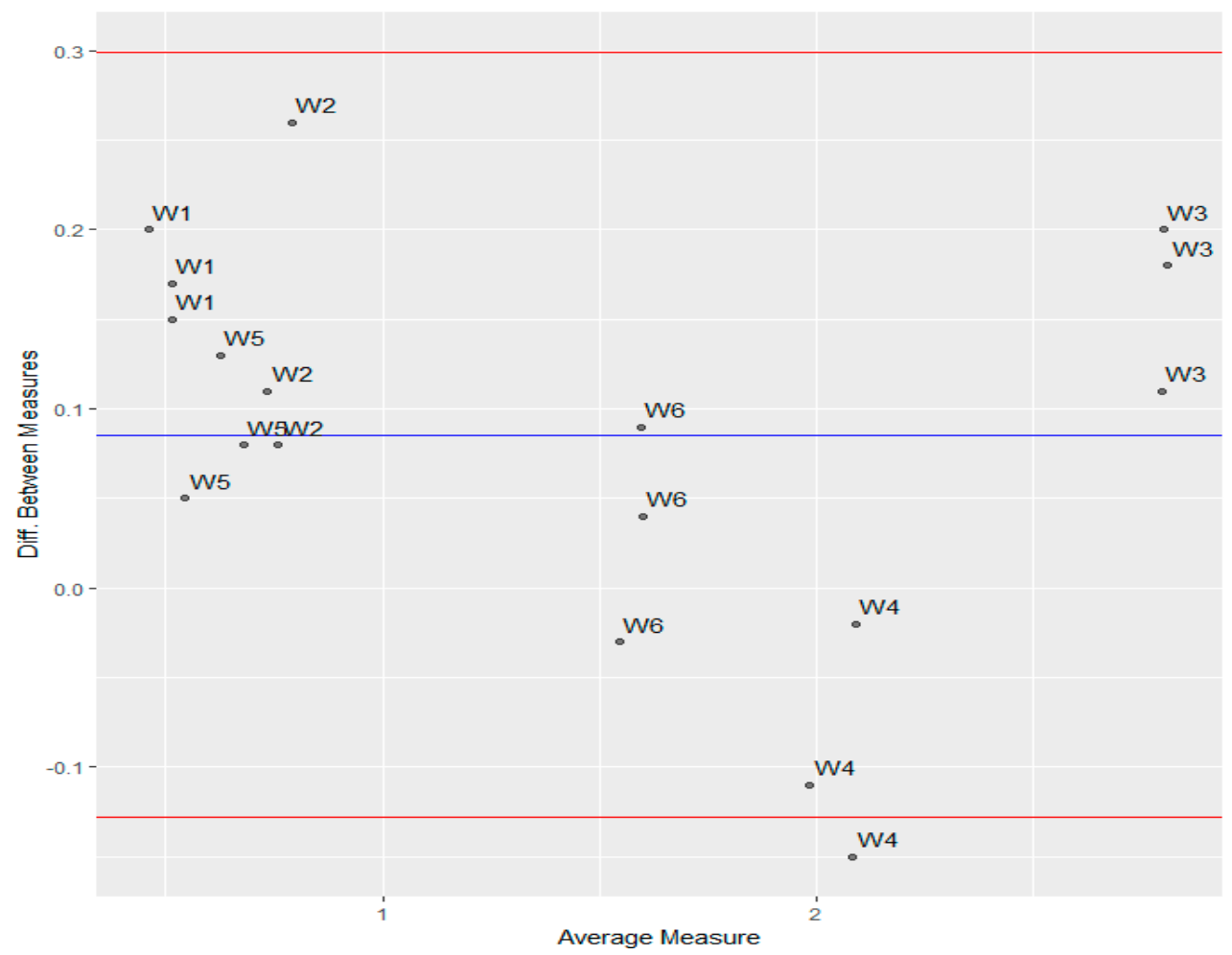

Figure 4. Bland-Altman plot of comparison of two methods (IAM-HLPC and ICP.MS). Blue line represents the mean of differences and red lines are lower and upper bounds of $95 \%$ confidence interval for the mean value. 


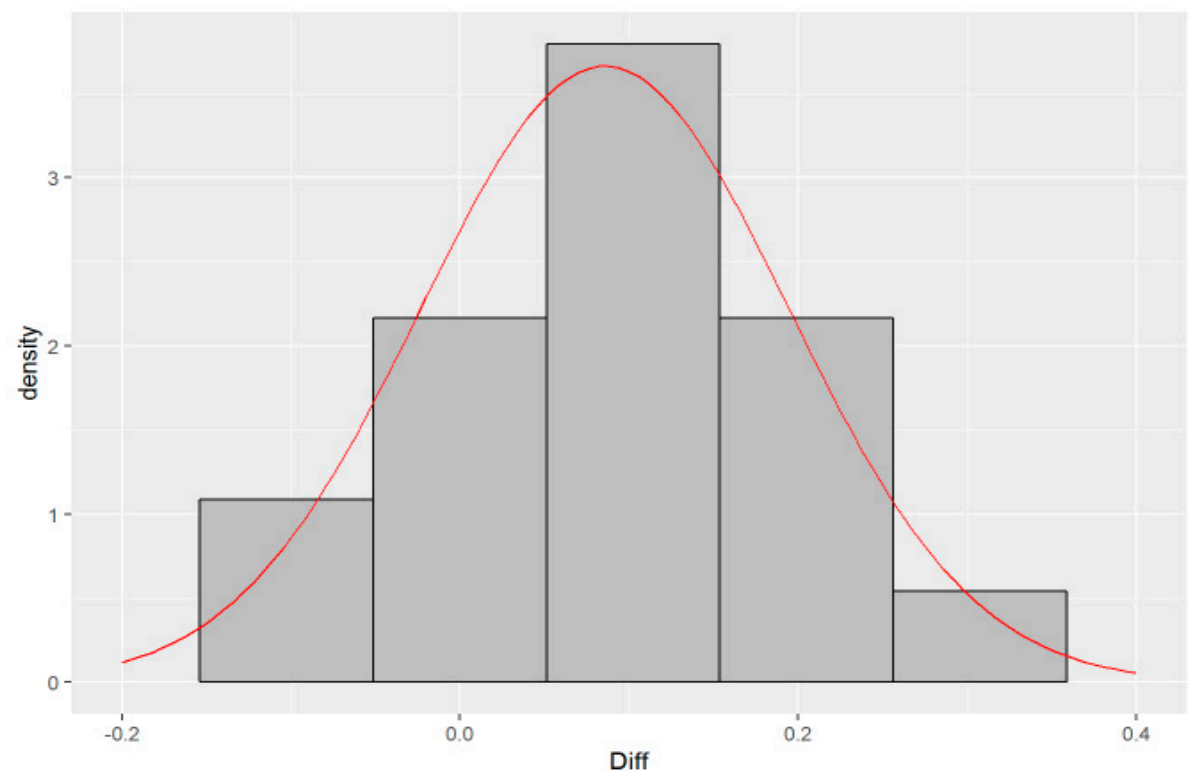

Figure 5. Histogram of differences of measurements with a density of normal distribution.

\subsection{Interferences of Coexisting Ions}

The effects of representative potential interfering ionic species in mineral water samples like $\mathrm{HCO}_{3}{ }^{-}, \mathrm{Cl}^{-}, \mathrm{SO}_{4}{ }^{2-}, \mathrm{F}^{-}$, and $\mathrm{Br}^{-}$were also tested. To perform this study, aqueous solutions containing a constant iodide concentration and different coexisting ions were subjected to the developed procedure. Iodide absorbs at $226 \mathrm{~nm}$ while the other anions $\left(\lambda_{\max }=210 \mathrm{~nm}\right)$ remain undetected at this wavelength. Tables 6 and 7 show the tolerance limits of the interfering ions. The tolerance limit (TL) of coexisting ions was defined as the largest amount, which makes variation less than $5 \%$ in the peak height or area.

Table 6. The tolerance limits of the interfering ions in the height of the iodide peak.

\begin{tabular}{|c|c|c|c|c|c|c|}
\hline $\begin{array}{l}\text { Statistical Evaluation of } \\
\text { the Iodide Peak Height } \\
\qquad\left[\mathrm{I}^{-}\right]=4 \mathrm{ppm}\end{array}$ & $\mathrm{H}_{2} \mathrm{O}$ & $\begin{array}{c}\mathrm{HCO}_{3}^{-} \\
{[1000 \text { ppm }]}\end{array}$ & $\begin{array}{c}\mathrm{Cl}^{-} \\
{[1000 \mathrm{ppm}]}\end{array}$ & $\begin{array}{c}\mathrm{SO}_{4}{ }^{2-} \\
{[100 \mathrm{ppm}]}\end{array}$ & $\begin{array}{c}F^{-} \\
{[10 \mathrm{ppm}]}\end{array}$ & $\begin{array}{c}\mathrm{Br}^{-} \\
{[10 \mathrm{ppm}]}\end{array}$ \\
\hline Average peak height & 6188.50 & 6209.67 & 6263.67 & 6138.67 & 6140.33 & 5890.33 \\
\hline SD & 254.26 & 100.01 & 59.70 & 274.97 & 109.70 & 157.02 \\
\hline $\mathrm{CV}$ & 4.11 & 1.61 & 0.95 & 4.48 & 1.79 & 2.67 \\
\hline Tolerance limit [\%] & - & 0.3 & 1.2 & 0.8 & 0.7 & 4.8 \\
\hline
\end{tabular}

Table 7. The influence of selected anions on the surface area of iodine peaks in the standard solutions.

\begin{tabular}{ccccccc}
\hline $\begin{array}{c}\text { Statistical Evaluation of } \\
\text { the Iodide Peak Area } \\
{[\mathbf{I}-\mathbf{~ = ~ 2 ~} \mathbf{~ p p m}}\end{array}$ & $\mathbf{H}_{\mathbf{2}} \mathbf{O} \begin{array}{c}\mathbf{H C O}_{\mathbf{3}}{ }^{-} \\
{[\mathbf{1 0 0 0} \mathbf{~ p m}]}\end{array}$ & $\begin{array}{c}\mathbf{C l}^{-} \\
{[\mathbf{1 0 0 0} \mathbf{~ p p m}]}\end{array}$ & $\begin{array}{c}\mathbf{S O}_{\mathbf{4}}{ }^{\mathbf{2}} \\
{[\mathbf{1 0 0} \mathbf{~ p p m}]}\end{array}$ & $\begin{array}{c}\mathbf{F}^{-} \\
{[\mathbf{1 0} \mathbf{~ p p m}]}\end{array}$ & $\begin{array}{c}\mathbf{B r}^{-} \\
{[\mathbf{1 0} \mathbf{~ p p m}]}\end{array}$ \\
\hline Average peak area & $232,474231,092.7$ & $233,938.9$ & $230,291.6$ & $230,719.1$ & $225,425.5$ \\
\hline SD & 3185.093122 .82 & 3182.58 & 2255.27 & 1715.77 & 4106.21 \\
\hline CV & 1.37 & 1.35 & 1.36 & 0.98 & 0.74 & 1.82 \\
\hline Tolerance limit [\%] & 0.6 & 0.6 & 0.9 & 0.8 & 3.0 \\
\hline
\end{tabular}

The presence of bromide provides the highest value of the tolerance limit considering the peak height $(4.8 \%)$ and its area (3.0), but both of them were still smaller than $5 \%$. Iodide can easily be detected by UV absorbance without interference from other anions. Proposed conditions can be classified as specific for iodide determination since it was either separated from potentially interfering 
ions, which can be present in mineral water samples at a high concentration or identified by its retention (6 minutes) at absorption maximum $(226 \mathrm{~nm})$.

\section{Experimental}

\subsection{Materials and Sample}

Deionized and purified water by ULTRAPURE Millipore Direct-Q 3UV-R (Merck, Darmstadt, Germany) of the resistivity $18.2 \mathrm{M} \Omega \mathrm{cm}$ was used to prepare all the aqueous solutions. Sodium chloride was sourced from POCH (Gliwice, Poland). A stock standard solution of potassium iodide (100 $\mathrm{mg} \mathrm{L}^{-1}$ ) was prepared from potassium iodide (Merck, Darmstadt, Germany). Mineral water samples were purchased from a local market (Lublin, Poland). They were stored at $4{ }^{\circ} \mathrm{C}$ in the refrigerator. The working standard solutions were prepared immediately before use.

\subsection{HPLC Conditions}

Chromatographic measurements were made on a LaChrom HPLC Merck Hitachi (E. Merck, Darmstadt, Germany) equipped with a diode array detector (L-7455), pump (L-7100), interface (D-7000), and solvent degasser (L-7612). Chromatographic column IAM.PC.DD2 Regis HPLC $(4.6 \times 150 \mathrm{~mm}$, $10 \mu \mathrm{m}$, pore size: $300 \AA$ ) was purchased from Agilent Technologies (Santa Clara, CA, USA). Column temperature was controlled in the range of 15 to $50{ }^{\circ} \mathrm{C}$ by the thermostatic column compartment L-7350. Chromatographic data were acquired and processed by D-7000 HSM Software version 3.0 (E. Merck, Darmstadt, Germany). The mobile phases were filtered through a Nylon 66 membrane filter $(0.45 \mu \mathrm{m})$ Whatman (Maidstone, England) using a filtration apparatus. The eluent was prepared by dissolution inorganic salt $(\mathrm{NaCl})$ in water. The chromatography was carried out at room temperature. Retention data was recorded at a flow-rate of $0.5 \mathrm{~mL} \mathrm{~min}^{-1}$. The detection wavelength was set at $226 \mathrm{~nm}$ chosen accordingly with the recorded spectra by the DAD detector ranging from 190 to $400 \mathrm{~nm}$. A sample solution was injected twice ranging from 3 to $20 \mu \mathrm{L}$.

\subsection{ICP-MS}

To validate the proposed method, iodide was assayed with the ICP-MS system. Analysis was carried out using an inductively coupled plasma mass spectrometer (ICP-MS), Varian MS-820 (Mulgrave, Victoria, Australia) coupled to a cross-flow nebulizer and a Scott spray chamber. The concentration was determined after diluting the solution with $0.5 \%(v / v)$ tetramethyhylammonium hydroxide (TMAH, Sigma-Aldrich, St. Louis, MO, USA) and adding tellurium as an internal standard. Standard solutions of tellurium with purity of $99.999 \%$ were purchased from Ultra Scientific (North Kingstown, RI, USA). Argon gas with a purity of $99.999 \%$ was purchased from the Messer Group (Bad Soden, Germany). All reagents were of an analytical grade unless specified otherwise. Deionized water with a resistivity of $18.2 \mathrm{M} \Omega / \mathrm{cm}$ was obtained from a HLP-20 system (Hydrolab, Straszyn, Poland).

\subsection{Method Optimization and Validation}

The interactions among process variables such as analyte's concentration and injection volume were determined by the RSA (Response Surface Analysis). The effect of concentration and injection volume was found to range from 5 to $100 \mathrm{ppm}$ (tj. 5, 10, 15, 25, 50, 75, and $100 \mathrm{ppm})$ and $3-20 \mu \mathrm{L}(3,5$, $10,15$, and $20 \mu \mathrm{L})$. The experimental data was developed by using the open source R program [48].

The method validation was carried out according to the guidelines ICH Q2 (R1) [42,49]. The linear range was calculated from a calibration curve made by injecting standards of iodide in triplicate at 10 concentration levels $(0.5,1.0,2.0,3.0,4.0,6.0,8.0,10.0)$ between 0 and $10 \mathrm{mg} \mathrm{L}^{-1}$. The limits of detection (LOD) and quantification (LOQ) correspond to 3 and 10 times the signal-to-noise ratio, respectively. Accuracy of the method was assessed using the determination of iodide recovery. The sample matrix (canal water) was spiked with a known concentration of iodide at three 
concentration levels of 2,5 , and $10 \mathrm{mg} \mathrm{L}^{-1}$ and the percentage of recoveries (R) of the spike standard were calculated as follows:

$$
\mathrm{R}(\%)=(\mathrm{Cm}-\mathrm{Co}) / \mathrm{m} \times 100
$$

where $\mathrm{Cm}$ is a value of iodide in a spiked sample, Co is the value of iodide in a sample, and $\mathrm{m}$ is the amount of iodide spiked. Specificity of the method was estimated by measuring the response of the investigated analyte (peak height) at a concentration of $4 \mathrm{mg} \mathrm{L}^{-1}$ in the presence of the high concentration of the potentially interfering components such as $\mathrm{HCO}_{3}^{-}\left(1000 \mathrm{mg} \mathrm{L}^{-1}\right)$, $\mathrm{Cl}^{-}\left(1000 \mathrm{mg} \mathrm{L}^{-1}\right), \mathrm{SO}_{4}{ }^{2-}\left(100 \mathrm{mg} \mathrm{L}^{-1}\right), \mathrm{F}^{-}\left(10 \mathrm{mg} \mathrm{L}^{-1}\right)$, and $\mathrm{Br}^{-}\left(10 \mathrm{mg} \mathrm{L}^{-1}\right)$.

\subsection{Data Analysis}

Multiple regression analysis was performed by using Microsoft Excel 2010. Experimental values were expressed as means \pm SD. The Shapiro-Wilk's W test for detecting a normal distribution of data were performed by the use of Statistica v. 12. The Bland-Altman plot was done in an R-statistical programing environment ( $R$ Core Team 2018) [48].

\section{Conclusions}

In the present study, a commercial phosphatidylcholine column IAM.PC.DD2 Regis HPLC was applied for the quantification of iodide in mineral water samples. The obtained results agreed well with ICP-MS used as the reference one, which indicates good performance of both methods for iodide determination. The main advantage of the current work is the simple instrumentation covering HPLC-DAD, which is considered to be a standard in most laboratories. Comparing the current methodology with those previously reported in the literature [50], the method utilizing the HPLC-DAD system with Mixed-Mode WAX-1 column, regarding linearity, sensitivity, precision, and recovery, and the phosphatidylcholine column ensured about two times shorter retention time (current method: $5.8 \mathrm{~min}$, reported method: $10.8 \mathrm{~min}$ ). In addition, it ensured a ten times smaller LOD value (current method: $22.84 \mu \mathrm{g} \mathrm{L}^{-1}$, reported method: $200 \mu \mathrm{g} \mathrm{L}^{-1}$ ) and a narrower range of recovery (current method: $98.5-100.2 \%$, reported method: $92.6-108.9 \%$ ). In conclusion, the presented results prove the usability of the IAM.PC.DD2 Regis HPLC column for iodide determination in aqueous samples.

Author Contributions: Conceptualization and writing J.F., M.T.-M., HPLC/DAD analysis J.K., Statistical analysis E.B. and W.F.

Funding: This research received no external funding.

Conflicts of Interest: The authors declare no conflict of interest.

\section{References}

1. Zimmermann, M.B.; Jooste, P.L.; Pandav, C.S. Iodine-deficiency disorders. Lancet 2008, 372, 1251-1262. [CrossRef]

2. World Health Organization/United Nations Children's Fund/International Council for Control of Iodine Deficiency Disorders. Assessment of Iodine Deficiency Disorders and Monitoring Their Elimination: A Guide for Programme Managers, 3rd ed.; World Health Organization: Geneva, Switzerland, 2007.

3. Zimmermann, M.B. Iodine deficiency. Endocr. Rev. 2009, 30, 376-408. [CrossRef]

4. Delange, F; Bürgi, H.; Chen, Z.P.; Dunn, J.T. World status of monitoring of iodine deficiency disorders control programs. Thyroid 2002, 12, 915-924. [CrossRef] [PubMed]

5. Li, H.-B.; Chen, F.; Xu, X.-R. Determination of iodide in seawater and urine by size exclusion chromatography with iodine-starch complex. J. Chromatogr. A 2001, 918, 335-339. [CrossRef]

6. Wisnu, C. Determination of iodine species content in iodized salt and foodstuff during cooking. Int. Food Res. J. 2008, 15, 325-330.

7. Merian, E.; Anke, M.; Ihnat, M.; Stoeppler, M. Elements and Their Compounds in the Environment, 2nd ed.; Wiley-VCH: Weinheim, Germany, 2004; pp. 1457-1485. 
8. Food and Nutrition Board, Institute of Medicine. Dietary Reference Intakes; National Academy Press: Washington, WA, USA, 2001.

9. Hansen, V.; Yi, P.; Hou, X.; Aldahan, A.; Roos, P.; Possnert, G. Iodide and iodate in surface water of the Baltic Sea, Kattegat and Skagerrak. Sci. Total Environ. 2011, 412-413, 296-303. [CrossRef] [PubMed]

10. Gilfedder, B.S.; Petri, M.; Biester, H. Iodine speciation and cycling in fresh waters: A case study from a humic rich headwater lake (Mummelsee). J. Limnol. 2009, 68, 396-408. [CrossRef]

11. Schwehr, K.A.; Santschi, P.H. Sensitive determination of iodine species, including organo-iodine, for freshwater and seawater samples using high performance liquid chromatography and spectrophotometric detection. Anal. Chim. Acta 2003, 482, 59-71. [CrossRef]

12. Zhang, S.; Schwehr, K.A.; Ho, Y.F.; Xu, C.; Roberts, K.A.; Kaplan, D.I.; Brinkmeyer, R.; Yeager, C.M.; Santschi, P.H. A novel approach for the simultaneous determination of iodide, iodate and organo-Iodide for 127I and 129I in environmental samples using gas chromatography-mass spectrometry. Environ. Sci. Technol. 2010, 44, 9042-9048. [CrossRef] [PubMed]

13. Kumar, S.D.; Maiti, B.; Mathur, P.K. Determination of iodate and sulphate in iodized common salt by ion chromatography with conductivity detection. Talanta 2001, 53, 701-705. [CrossRef]

14. Rebary, B.; Paul, P.; Ghosh, P.K. Determination of iodide and iodate in edible salt by ion chromatography with integrated amperometric detection. Food Chem. 2010, 123, 529-534. [CrossRef]

15. Sandell, E.B.; Kolthoff, I.M. Chronometric catalytic method for the determination of micro quantities of iodine. J. Am. Chem. Soc. 1934, 56, 1426. [CrossRef]

16. Association of Officiating Analytical Chemists. Official Method of Analysis: Method 935.14, 18th ed.; AOAC International: Washington, DC, USA, 2005.

17. Association of Officiating Analytical Chemists. Official method of Analysis: Method 992.24, 18th ed.; AOAC International: Washington, DC, USA, 2005.

18. Kosminsky, L.; Bertotti, M. Determination of iodate in salt samples with amperometric detection at a molybdenum oxide modified electrode. Electroanalysis 1999, 11, 623-626. [CrossRef]

19. Shelor, C.P.; Dasgupta, P.K. Review of analytical methods for the quantification of iodine in complex matrices. Anal. Chim. Acta 2011, 702, 16-36. [CrossRef] [PubMed]

20. Zhang, W.; Mnatsakanov, A.; Hower, R.; Cantor, H.; Wang, Y. Urinary iodine assays and ionophore based potentiometric iodide sensors. Front. Biosci. 2005, 10, 88-93. [CrossRef] [PubMed]

21. Cataldi, T.R.I.; Rubino, A.; Laviola, M.C.; Ciriello, R. Comparison of silver, gold and modified platinum electrodes for the electrochemical detection of iodide in urine samples following ion chromatography. J. Chromatogr. B 2005, 827, 224-231. [CrossRef] [PubMed]

22. Judprasong, K.; Jongjaithet, N.; Chavasit, V. Comparison of methods for iodine analysis in foods. Food Chem. 2016, 193, 12-17. [CrossRef] [PubMed]

23. Association of Officiating Analytical Chemists. Official Method of Analysis: Method 992.22, 18th ed.; AOAC International: Washington, DC, USA, 2007.

24. Association of Officiating Analytical Chemists. Official Method of Analysis: Method 2012.14 and 2012.15, 18th ed.; AOAC International: Washington, DC, USA, 2012.

25. Wang, T.; Zhao, S.; Shen, C.; Tang, J.; Wang, D. Determination of iodate in table salt by transient isotachophoresis-capillary zone electrophoresis. Food Chem. 2009, 112, 215-220. [CrossRef]

26. Huang, X.; Li, Y.; Chen, Y.; Wang, L. Electrochemical determination of nitrite and iodate by use of gold nanoparticles/poly(3-methylthiophene) composites coated glassy carbon electrode. Sens. Actuators B Chem. 2008, 134, 780-786. [CrossRef]

27. Dionex Corporation. Determination of Iodide and Iodate in Seawater and Iodized Table Salt by HPLC With UV Detection (Application Note 236). Available online: http:/ / www.cromlab.es/Articulos/Columnas / HPLC/Thermo/Acclaim/WAX-1/81306-AN236-LC-Iodide-Seawater-15Sept2009-LPN2312.pdf (accessed on 28 March 2019).

28. Hurum, D.; Rohrer, J. Determination of Iodide in Seawater and Other Saline Matrices Using a Reagent-Free Ion Chromatography System with Suppressed Conductivity and UV Detections (Application Note 239). Available online: https://assets.thermofisher.com/TFS-Assets/CMD/Application-Notes/AN-239-ICIodide-Seawater-AN71348-EN.pdf (accessed on 28 March 2019).

29. Yamada, H.; Kajiyama, S.; Yonebayashi, K. Determination of trace amounts of iodine in soils by HPLC with fluorescence detection. Bunseki Kagaku 1995, 44, 1027-1032. [CrossRef] 
30. Yamada, H.; Kiriyama, T.; Onagawa, Y.; Hisamori, I.; Miyazaki, C.; Yonebayashi, K. Speciation of Iodine in Soils. Soil Sci. Plant Nutr. 1999, 45, 563-568. [CrossRef]

31. Hu, W.; Haddad, P.R.; Tanaka, K.; Mori, M.; Tekura, K.; Hase, K.; Ohno, M.; Kamo, N. Creation and characteristics of phosphatidylcholine stationary phases for the chromatographic separation of inorganic anions. J. Chromatogr. A 2003, 997, 237-242. [CrossRef]

32. Wiedmer, S.K.; Jussila, M.S.; Riekkola, M.L. Phospholipids and liposomes in liquid chromatographic and capillary electromigration techniques. Trends Anal. Chem. 2004, 23, 562-582. [CrossRef]

33. Giaginis, C.; Tsantili-Kakoulidou, A. Alternative measures of lipophilicity from octanol-water partitioning to IAM retention. J. Pharm. Sci. 2008, 97, 2984-3004. [CrossRef] [PubMed]

34. Barbato, F.; Di Martino, G.; Grumetto, L.; La Rotonda, M.I. Retention of quinolones on human serum albumin and alpha1-acid glycoprotein HPLC columns: Relationships with different scales of lipophilicity. Eur. J. Pharm. Sci. 2007, 30, 211-219. [CrossRef]

35. Lázaro, E.; Castillo, J.A.; Ráfols, C.; Rosés, M.; Clapés, P.; Torres, J.L. Immunomodulatory Activity of a New Family of Antioxidants Obtained from Grape Polyphenols. J. Agric. Food Chem. 2007, 55, 2901-2905. [CrossRef]

36. Zhang, W.N.; Hu, Z.X.; Liu, Y.; Feng, Y.Q.; Da, S.L. Study on interaction between drug and membrane by using liposome coated zirconia-magnesia chromatography. Talanta 2005, 67, 1023-1028. [CrossRef] [PubMed]

37. Barbato, F.; di Martino, G.; Grumetto, L.; La Rotonda, M. Prediction of drug-membrane interactions by IAM-HPLC: Effects of different phospholipid stationary phases on the partition of bases. Eur. J. Pharm. Sci. 2004, 22, 261-269. [CrossRef] [PubMed]

38. Ollila, F.; Halling, K.; Vuorela, P.; Vuorela, H.; Slotte, J.P. Characterization of flavonoid-biomembrane interactions. Arch. Biochem. Biophys. 2002, 399, 103-108. [CrossRef] [PubMed]

39. Sarr, F.S.; André, C.; Guillaume, Y.C. Statins (HMG-coenzyme A reductase inhibitors)-biomimetic membrane binding mechanism investigated by molecular chromatography. J. Chromatogr. B 2008, 868, 20-27. [CrossRef]

40. Mei, J.; Xu, J.R.; Xiao, Y.X.; Zhang, Q.R.; Feng, Y.Q. Immobilized phospholipid capillary electrophoresis for study of drug-membrane interactions and prediction of drug activity. Talanta 2008, 75, 104-110. [CrossRef] [PubMed]

41. Ito, K.; Hirokawa, T. Enhanced detection of iodide in seawater by ion chromatography using an ODS column coated with cetyltrimethyl ammonium. Anal. Sci. 2001, 17, 579-581. [CrossRef] [PubMed]

42. Ito, K.; Nomura, R.; Fujii, T.; Tanaka, M.; Tsumura, T.; Shibata, H.; Hirokawa, T. Determination of nitrite, nitrate, bromide, and iodide in seawater by ion chromatography with UV detection using dilauryl dimethyl ammonium-coated monolithic ODS columns and sodium chloride as an eluent. Anal. Bioanal. Chem. 2012, 404, 2513-2517. [CrossRef] [PubMed]

43. Rodriguez, E.S.; Setiawan, A.N.; Pope, S.; Haddad, P.R.; Nesterenko, P.N.; Paull, B. A simple and sensitive method for the determination of iodide and iodate in raw, ultraviolet- and ozone-treated aqua cultural seawater samples using ion chromatography coupled to an ultraviolet detector. Anal. Methods 2016, 8, 5587-5595. [CrossRef]

44. Giavarina, D. Understanding Bland Altman Analysis. Biochem. Med. 2015, 25, 141-151. [CrossRef] [PubMed]

45. Bland, J.M.; Altman, D.G. Statistical methods for assessing agreement between two methods of clinical measurement. Lancet 1986, 1, 307-310. [CrossRef]

46. Altman, D.G.; Bland, J.M. Measurement in Medicine: The Analysis of Method Comparison Studies. J. R. Stat. Soc. Ser. D 1983, 32, 307-317.

47. Bland, J.M.; Altman, D.G. Statistical Methods for Assessing Agreement Between Two Methods of Clinical Measurement. Int. J. Nurs. Stud. 2010, 47, 931-936. [CrossRef]

48. R Core Team R: A language and environment for statistical computing. R Foundation for Statistical Computing. Available online: https:/ /www.R-project.org/ (accessed on 8 February 2008). 
49. International Conference on Harmonization (ICH) of Technical Requirements for the Registration of Pharmaceuticals for Human Use, Validation of analytical procedures: Text and Methodology; ICH-Q2B: Geneva, Switzerland, 1996.

50. Nitscke, U.; Stengel, D.B. A new HPLC method for the detection of iodine applied to natural samples of edible seaweeds and commercial seaweed food products. Food Chem. 2015, 172, 326-334. [CrossRef]

Sample Availability: Samples of the investigated water are available from the authors.

(C) 2019 by the authors. Licensee MDPI, Basel, Switzerland. This article is an open access article distributed under the terms and conditions of the Creative Commons Attribution (CC BY) license (http:/ / creativecommons.org/licenses/by/4.0/). 